\title{
Necroptosis, necrosis and secondary necrosis converge on similar cellular disintegration features
}

\author{
T Vanden Berghe ${ }^{1,2,6}$, N Vanlangenakker ${ }^{1,2,6}$, E Parthoens ${ }^{3}$, W Deckers ${ }^{3}$, M Devos ${ }^{1,2}$, N Festjens ${ }^{1,2,4}$, CJ Guerin ${ }^{3}$, UT Brunk ${ }^{5}$, \\ W Declercq ${ }^{1,2}$ and $P$ Vandenabeele ${ }^{\star, 1,2}$
}

\begin{abstract}
Necroptosis, necrosis and secondary necrosis following apoptosis represent different modes of cell death that eventually result in similar cellular morphology including rounding of the cell, cytoplasmic swelling, rupture of the plasma membrane and spilling of the intracellular content. Subcellular events during tumor necrosis factor (TNF)-induced necroptosis, $\mathrm{H}_{2} \mathrm{O}_{2}$-induced necrosis and anti-Fas-induced secondary necrosis were studied using high-resolution time-lapse microscopy. The cellular disintegration phase of the three types of necrosis is characterized by an identical sequence of subcellular events, including oxidative burst, mitochondrial membrane hyperpolarization, lysosomal membrane permeabilization and plasma membrane permeabilization, although with different kinetics. $\mathrm{H}_{2} \mathrm{O}_{2}$-induced necrosis starts immediately by lysosomal permeabilization. In contrast, during TNF-mediated necroptosis and anti-Fas-induced secondary necrosis, this is a late event preceded by a defined signaling phase. TNF-induced necroptosis depends on receptor-interacting protein-1 kinase, mitochondrial complex I and cytosolic phospholipase $\mathrm{A}_{2}$ activities, whereas $\mathrm{H}_{2} \mathrm{O}_{2}$-induced necrosis requires iron-dependent Fenton reactions.
\end{abstract}

Cell Death and Differentiation (2010) 17, 922-930; doi:10.1038/cdd.2009.184; published online 11 December 2009

Cell death is essential for the elimination of unwanted or harmful cells during development, homeostasis and pathogenesis. Apoptosis is morphologically characterized by nuclear shrinkage and fragmentation, cellular condensation, membrane blebbing, formation of apoptotic bodies and activation of caspases. ${ }^{1}$ Research during the last decade clearly illustrates the important contribution of alternative forms of cell death in development and homeostasis. ${ }^{2}$ For a long time, necrosis has been considered an uncontrolled form of cell death, but accumulating evidence shows that necrotic cell death is carried out by complex signal transduction pathways and execution mechanisms. ${ }^{3,4}$ In vitro, necrosis is morphologically characterized by rounding of the cell, cytoplasmic swelling (oncosis), presence of dilated organelles and absence of chromatin condensation. ${ }^{1,4}$

Necroptosis refers to a regulated form of necrosis, which is biochemically defined as a form of cell death that is dependent on the serine-threonine kinase receptor-interacting protein 1 (RIP1). ${ }^{4-6}$ The (patho)physiological relevance of necroptosis has been underestimated for a long time because of the absence of a defined biochemical marker. This has now changed with the identification of necrostatins. ${ }^{1,6}$ Using the
RIP1 inhibitor, necrostatin-1 (Nec-1), ${ }^{7,8}$ the contribution of necroptosis has been demonstrated in a wide range of pathological cell death events, such as ischemic brain injury, myocardial infarction, excitotoxicity and chemotherapyinduced cell death. ${ }^{8}$ RIP3, which functions in close concert with RIP1, was recently shown to be required for tumor necrosis factor (TNF)-induced necroptosis when apoptotic signaling is blocked. ${ }^{9}$ Apparently, RIP3 activates glycolysisand glutaminolysis-enhancing bioenergetics, with concomitant complex I-mediated reactive oxygen species (ROS) production. ${ }^{9}$ Other mediators of TNF-induced necroptosis are calcium, ceramide, cytosolic phospholipase A2 $\left(\mathrm{CPLA}_{2}\right)$ and lysosomal membrane permeabilization (LMP). ${ }^{4}$

Severe oxidative stress has also been associated with LMP and consequent necrosis. ${ }^{10}$ Extracellular application of $0.01-1 \mathrm{mM}$ peroxide is physiologically relevant and broadly mimics the release of endogenous $\mathrm{H}_{2} \mathrm{O}_{2} \cdot{ }^{11}$ For example, activated neutrophils generate up to $6 \times 10^{-14} \mathrm{~mol} \mathrm{H}_{2} \mathrm{O}_{2} / \mathrm{h}$ per cell, generating a local concentration of $10-100 \mu \mathrm{M} \mathrm{H}_{2} \mathrm{O}_{2}{ }^{12}$ Lysosomes, which are rich in free iron and lack enzymes for $\mathrm{H}_{2} \mathrm{O}_{2}$ degradation, favor Fenton-type-mediated generation of reactive hydroxyl radicals. ${ }^{13}$ This formation of hydroxyl

\footnotetext{
${ }^{1}$ Department for Molecular Biomedical Research, VIB, Technologiepark 927, Ghent 9000, Belgium; '2Department of Biomedical Molecular Biology, Ghent University, Technologiepark 927, Ghent 9000, Belgium; ${ }^{3}$ Microscopy Core Facility, Department for Molecular Biomedical Research, VIB - Ghent University, Technologiepark 927, Ghent 9000, Belgium; ${ }^{4}$ Unit for Molecular Glycobiology, Department for Molecular Biomedical Research, VIB, Technologiepark 927, Ghent 9000, Belgium and ${ }^{5}$ Faculty of Health Sciences, Division of Pharmacology, Linkoping University, Hälsouniversitetet, Linköping SE-581 83, Sweden

${ }^{*}$ Corresponding author: P Vandenabeele, Department for Molecular Biomedical Research, VIB - Ghent University, Technologiepark 927, Zwijnaarde-Gent 9000, Belgium. Tel: + 3293313 760; Fax: + 3293313 609; E-mail: Peter.Vandenabeele@dmbr.vib-UGent.be

${ }^{6}$ These authors contributed equally to this work.

Keywords: necrosis; time-lapse; RIP1; Fenton reactions; lysosomes

Abbreviations: BEL, bromoenol lactone; BHA, butylated hydroxyanisole; CCCP, carbonyl cyanide m-chlorophenyl hydrazone; CM-CH $2 \mathrm{DCFDA}, 5-(a n d-6)$ chloromethyl-2', $7^{\prime}$-dichlorodihydrofluorescein diacetate, acetyl ester; $\mathrm{CPLA}_{2}$, cytosolic phospholipase $\mathrm{A}_{2}$; DAMP, damage-associated molecular patterns; DFO, desferrioxamine; DPI, diphenylene iodonium; LMP, lysosomal membrane permeabilization; MEF, mouse embryonic fibroblasts; MTP, mitochondrial transmembrane potential; MTT, 2,5-diphenyltetrazolium bromide; NDUFAF1, NADH dehydrogenase (ubiquinone) 1- $\alpha$ subcomplex, assembly factor 1; Nec, necrostatin; PI, propidium iodide; PMP, plasma membrane permeabilization; RIP, receptor-interacting protein; ROS, reactive oxygen species; SIH, salicylaldehyde isonicotinoyl hydrazone; TMRM, tetramethyl rhodamine methyl ester; TNF, tumor necrosis factor

Received 04.2.09; revised 06.10.09; accepted 30.10.09; Edited by PH Krammer; published online 11.12.09
} 
radicals results in enhanced lipid peroxidation of membranes, and consequent LMP. ${ }^{14}$ Scavenging iron in therapy, using metal-protein-attenuating compounds, has been proven to be beneficial in neurodegenerative diseases, thereby making inhibition of LMP and consequent necrosis an interesting therapeutic strategy. ${ }^{15}$

The different subcellular events in necrotic signaling are elusive. Therefore, this study analyzed, by high-resolution live-cell imaging, the occurrence of ROS generation, changes in mitochondrial transmembrane potential (MTP), LMP and plasma membrane permeabilization (PMP) during TNFmediated necroptosis, $\mathrm{H}_{2} \mathrm{O}_{2}$-induced necrosis and anti-Fasmediated secondary necrosis in the same cellular context, that is, in L929sAhFas cells.

\section{Results}

ROS production during TNF-induced necroptosis and $\mathrm{H}_{2} \mathrm{O}_{2}$-induced necrosis. A comparative morphological analysis of TNF-induced necroptosis and $\mathrm{H}_{2} \mathrm{O}_{2}$-induced necrosis in L929sAhFas cells by time-lapse imaging confirmed the absence of apoptotic features. Instead, we observed that both stimuli induced rounding of the cell, followed by cellular swelling and granulation of the cytoplasm. Finally, the plasma membrane gets an inflated 'balloon-like' appearance on its rupture (Supplementary Figure 1a-h). In both TNF- and $\mathrm{H}_{2} \mathrm{O}_{2}$-induced cell death, no caspase activity was detected, in contrast to anti-Fas-induced apoptosis (Supplementary Figure $1 \mathrm{i}$ and $\mathrm{j}$ ). TNF- and $\mathrm{H}_{2} \mathrm{O}_{2}$-induced cell death elicits intracellular oxidative stress, which is monitored using $\mathrm{CM}-\mathrm{H}_{2}$ DCFDA as a probe in live-cell imaging. In parallel, PMP was determined by propidium iodide $(\mathrm{PI})$ uptake and taken as a reference end point in all experiments.

On TNF stimulation, ROS generation gradually increased without major morphological changes (Figure $1 \mathrm{a}$ and $\mathrm{b}$, between points $\mathrm{t} 1$ and $\mathrm{t} 3$, Supplementary video 1a), followed by an oxidative burst before PMP. In contrast, in $\mathrm{H}_{2} \mathrm{O}_{2}-$ induced necrosis, the onset of an oxidative burst occurred more rapidly (Figure 1c and d, Supplementary video 2a). In both conditions, the beginning of the ROS peak coincided with the initiation of typical necrotic features, such as rounding and swelling of cells (Figure 1a, Supplementary video $1 \mathrm{~b}$ and Figure 1c, Supplementary video 2b). None of the above-mentioned observations were seen in unstimulated cells (Supplementary Figure 2a). Conclusively, TNF elicits a modest increase in ROS production during the signaling phase, which is followed by an oxidative burst coinciding with a
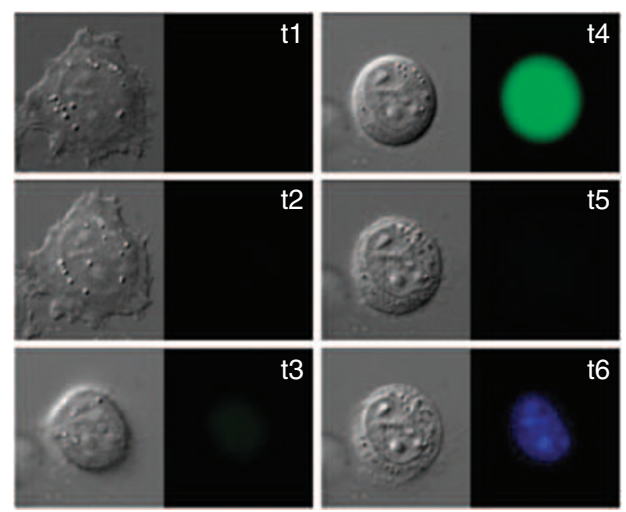

C
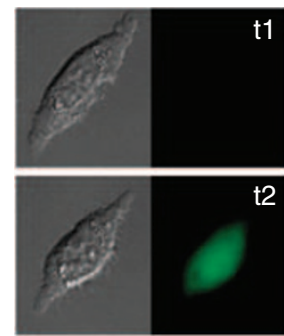

.

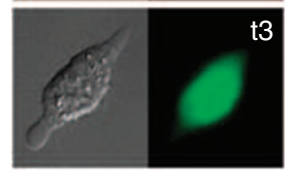

$\mathrm{H}_{2} \mathrm{O}_{2}$

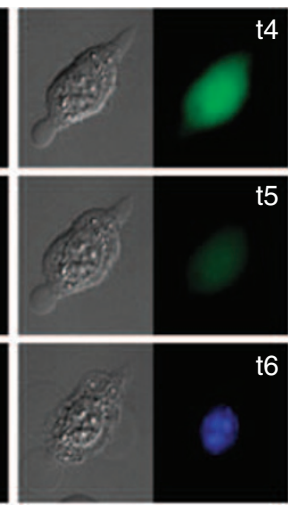

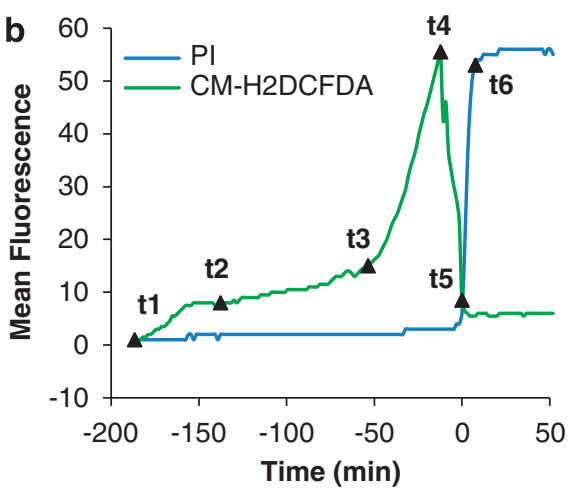

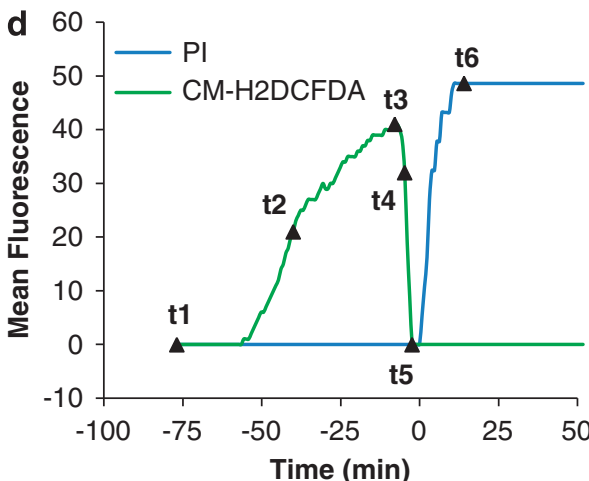

Figure 1 Live-cell imaging reveals differential ROS formation in TNF- and $\mathrm{H}_{2} \mathrm{O}_{2}$-induced necrosis. Light fluorescence microscopic analysis of ROS formation in L929sAhFas cells at different time points (time intervals of 92 and $47 \mathrm{~s}$, respectively) after induction of necrosis by (a) TNF or (c) $\mathrm{H}_{2} \mathrm{O}_{2}$ and subsequent PMP. Cells were loaded with $\mathrm{CM}-\mathrm{H}_{2} \mathrm{DCFDA}$ (green, indicating ROS accumulation) and PI (blue, indicating PMP). Graphic representations of the mean fluorescent intensities of CM- $\mathrm{H}_{2} \mathrm{DCFDA}$ and PI during necrosis of a representative single cell induced by (b) TNF or $(\mathbf{d}) \mathrm{H}_{2} \mathrm{O}_{2}$. The mean intensities of the subcellular fluorescent images (t1-t6) represented in (a) and (c) are marked by $\boldsymbol{\Delta}$ in (b) and (d), respectively 
the cellular disintegration phase, whereas $\mathrm{H}_{2} \mathrm{O}_{2}$ induces a high level of ROS generation starting shortly after $\mathrm{H}_{2} \mathrm{O}_{2}$ treatment.

\section{Mitochondrial transmembrane potential in TNF-induced} necroptosis and $\mathrm{H}_{2} \mathrm{O}_{2}$-induced necrosis. Another typical biochemical event during cell death is modulation of MTP. Reduction of MTP is an early event in apoptosis. ${ }^{16}$ In TNF-induced necroptosis, however, increased MTP has been reported. ${ }^{17}$ To follow the changes in MTP during TNF- and $\mathrm{H}_{2} \mathrm{O}_{2}$-induced cell death, cells were loaded with TMRM, which is sequestered by actively respiring mitochondria, and analyzed by time-lapse microscopy. PMP was determined by SYTOX Green uptake. In agreement with Goossens et al., ${ }^{17}$ we observed hyperpolarization of mitochondria with biphasic kinetics (Figure 2a and $b$, points t2-t6), starting shortly before the onset of cellular rounding (Supplementary video $3 a$ and b). In contrast, $\mathrm{H}_{2} \mathrm{O}_{2}$ caused immediate hyperpolarization that rapidly returned to baseline (Figure $2 \mathrm{c}$ and $\mathrm{d}$, Supplementary video $4 a$ and b). None of the abovementioned observations were seen in non-dying cells (Supplementary Figure 2b). Therefore, we conclude that both forms of necrotic cell death exhibit mitochondrial hyperpolarization, although with different kinetics.

Lysosomal membrane permeabilization during TNFinduced necroptosis and $\mathrm{H}_{2} \mathrm{O}_{2}$-induced necrosis. As LMP has been reported as a crucial event during apoptosis and necrosis, ${ }^{14}$ we next analyzed lysosomal integrity using LysoTracker Red DND-99. During TNF-induced necroptosis, the onset of the typical oncosis morphology coincided with the start of LMP (Figure $3 a$ and b, point t4, Supplementary video $5 \mathrm{a}$ and $\mathrm{b}$ ), just after the onset of mitochondrial hyperpolarization (Figure 2a) and before oxidative burst (Figure 1a). In contrast, on addition of $\mathrm{H}_{2} \mathrm{O}_{2}$, lysosomes rapidly started to leak (Figure $3 c$ and $d$, Supplementary video $6 \mathrm{a}$ and $\mathrm{b})$, which persists longer than in TNF-induced a
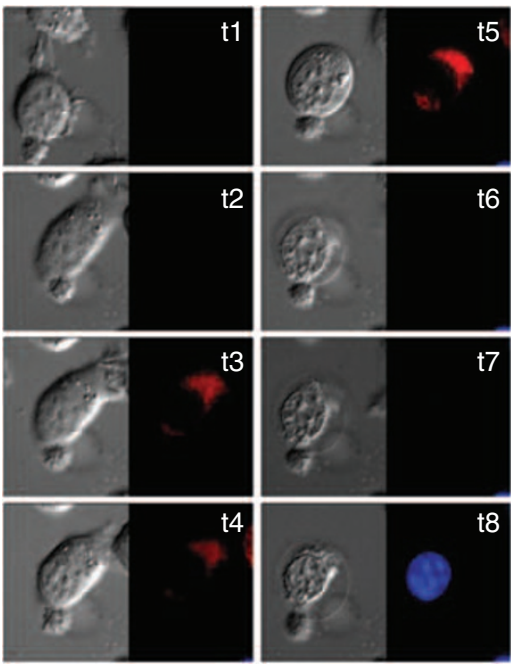

C
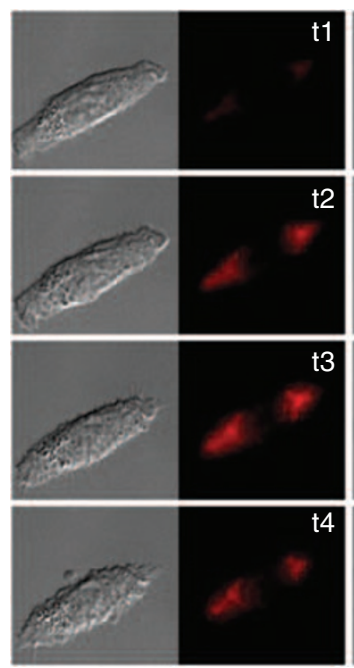

$\mathrm{H}_{2} \mathrm{O}_{2}$
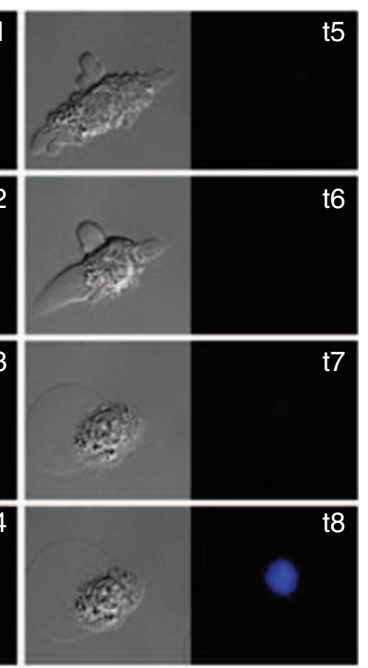

b

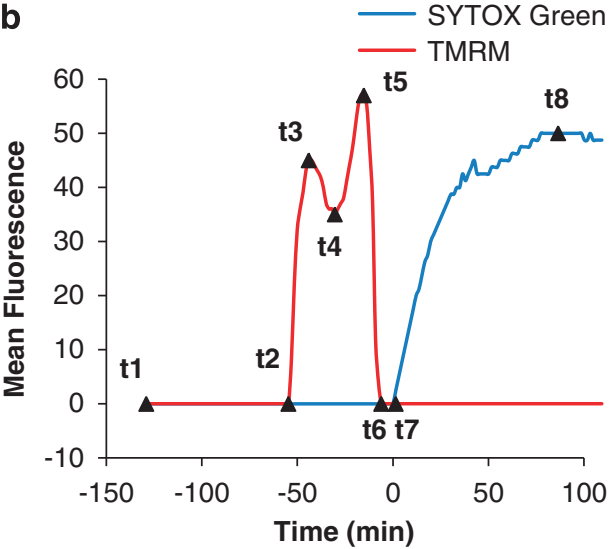

d

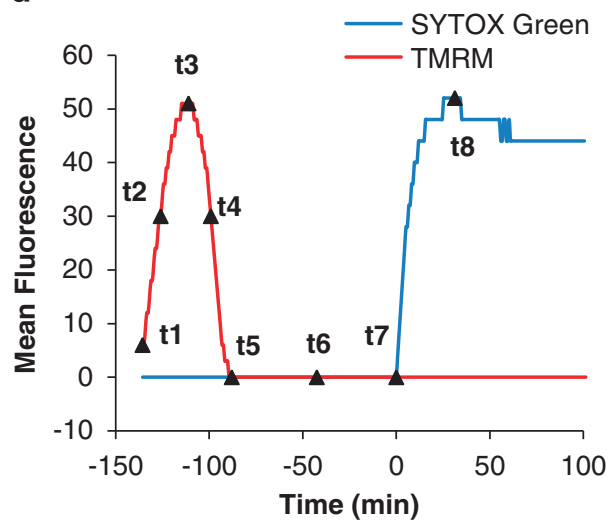

Figure 2 Live-cell imaging reveals a differential transient increase in MTP in TNF- and $\mathrm{H}_{2} \mathrm{O}_{2}$-induced necrosis. Light fluorescence microscopic analysis of MTP in L929sAhFas cells at different time points (time intervals of 91 and $45 \mathrm{~s}$, respectively) after induction of necrosis by (a) TNF or (c) $\mathrm{H}_{2} \mathrm{O}_{2}$, and subsequent PMP. Cells were loaded with TMRM (red, directly proportional to MTP) and SYTOX Green (blue, indicating PMP). Graphic representations of the mean intensities of TMRM and SYTOX Green during necrosis of a representative single cell induced by (b) TNF or (d) $\mathrm{H}_{2} \mathrm{O}_{2}$ in L929sAhFas cells. The mean intensities of the subcellular fluorescent images (t1-t8) represented in (a) and (c) are marked by $\boldsymbol{\Delta}$ in (b) and (d), respectively 
a

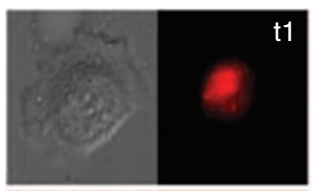

TNF
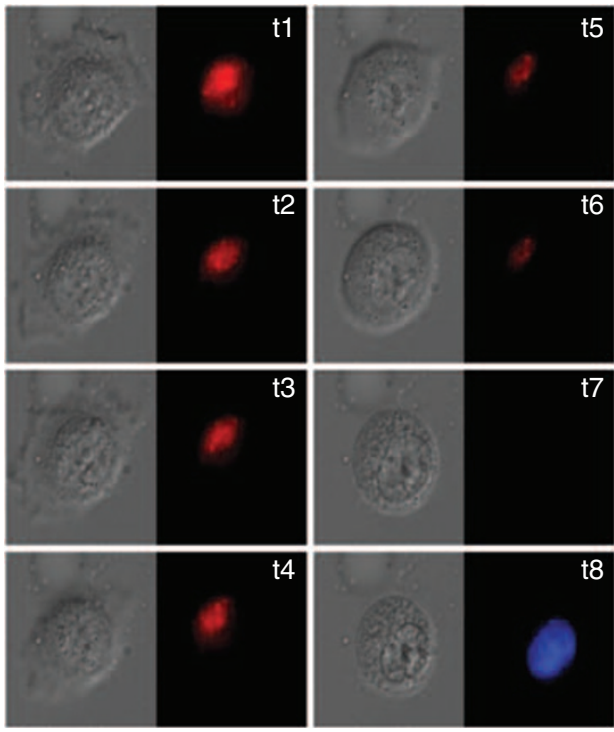

b

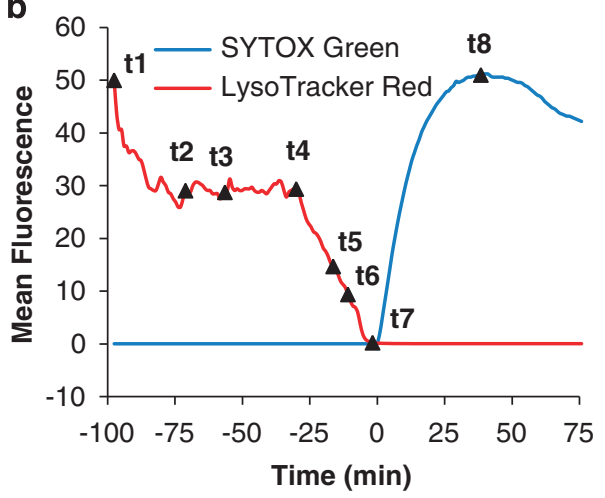

c

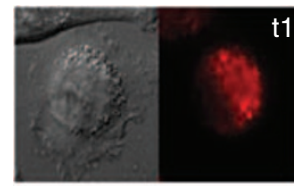

$\mathrm{H}_{2} \mathrm{O}_{2}$
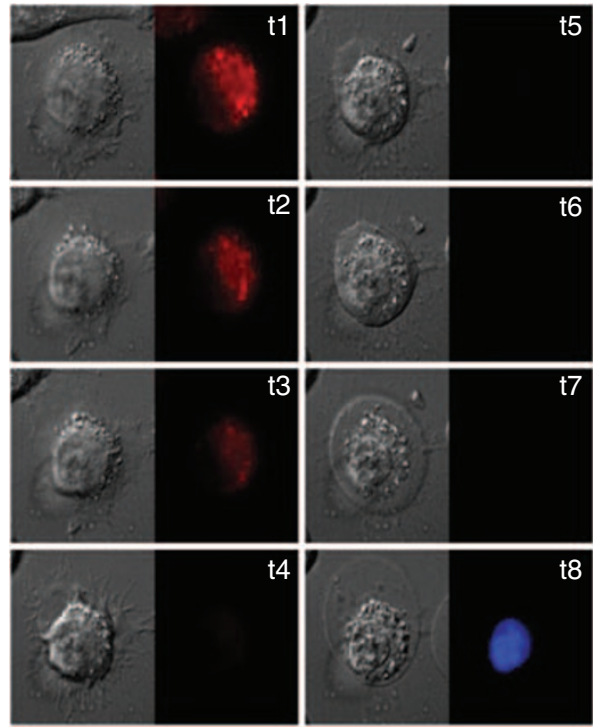

d

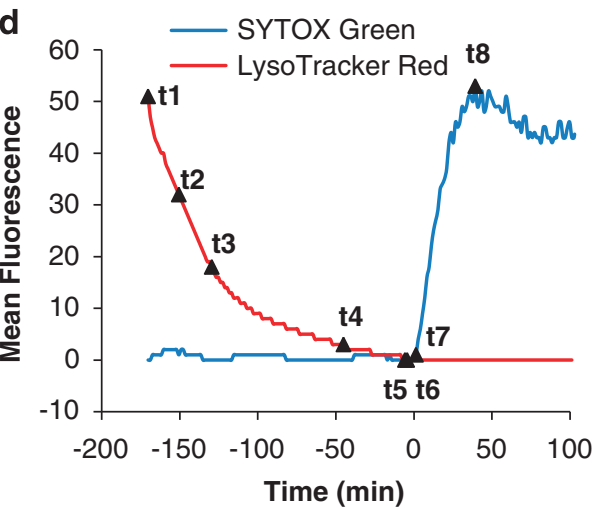

Figure 3 Live-cell imaging reveals distinct lysosomal leakage in TNF- and $\mathrm{H}_{2} \mathrm{O}_{2}$-induced necrosis. Light fluorescence microscopic analysis of lysosomal leakage in L929sAhFas cells at different time points (time intervals of $55 \mathrm{~s}$ and $85 \mathrm{~s}$, respectively) after induction of necrosis by (a) TNF or (c) $\mathrm{H}_{2} \mathrm{O}_{2}$, and subsequent PMP. Cells were loaded with LysoTracker Red DND-99 (red, inversely proportional to lysosomal leakage) and SYTOX Green (blue, indicating PMP). Graphic representations of the mean intensities of LysoTracker Red DND-99 and SYTOX Green during necrosis of a representative single cell induced by (b) TNF or (d) $\mathrm{H}_{2} \mathrm{O}_{2}$ in $\mathrm{L}^{2} 29 \mathrm{sAhFas} \mathrm{cells.} \mathrm{The} \mathrm{mean}$ intensities of the subcellular fluorescent images (t1-t8) represented in (a) and (c) are marked by $\boldsymbol{\Delta}$ in (b) and (d), respectively

necroptosis. No LMP was seen when monitoring unstimulated cells (Supplementary Figure 2c). These data demonstrate that lysosomal disruption is a late event in TNF-induced necroptosis and an early event in $\mathrm{H}_{2} \mathrm{O}_{2}$ induced necrosis.

ROS production, mitochondrial hyperpolarization and LMP during secondary necrosis. The above results demonstrate that TNF-induced necroptosis and $\mathrm{H}_{2} \mathrm{O}_{2}$ induced necrosis are characterized by LMP, mitochondrial hyperpolarization, oxidative burst and PMP, but they occur with different kinetics. Apoptosis is characterized by a caspase-dependent signaling phase and a burial phase during which apoptotic cells are rapidly recognized and taken up by phagocytes. In the absence of phagocytic capacity, apoptotic cells proceed to secondary necrosis characterized by the same features of necrotic cell death. ${ }^{18}$ Therefore, we examined whether the subcellular events described above also occurs during secondary necrosis after antiFas-mediated apoptosis in L929sAhFas cells. Secondary necrosis, similar to primary necrosis, is characterized by oxidative burst (Figure 4a, Supplementary video 7), mitochondrial hyperpolarization (Figure 4b, points t1-t2, Supplementary video 8) and LMP (Figure 4c, Supplementary video 9).

Differential roles of RIP1, mitochondrial complex I and cPLA $_{2}$ during different types of necrosis. The kinase activity of RIP1 is crucial for death receptor-induced necrosis. ${ }^{19,20}$ Moreover, it has been reported that $\mathrm{H}_{2} \mathrm{O}_{2}$ induced necrosis is also reduced in RIP1-deficient mouse embryonic fibroblasts (MEF). ${ }^{21}$ Using RNA interference, we confirmed the importance of RIP1 in TNF-induced necroptosis, but we did not observe any effect on $\mathrm{H}_{2} \mathrm{O}_{2}$ induced necrosis or on anti-Fas-induced secondary necrosis (Figure 5a). Nec-1, a chemical compound that directly 

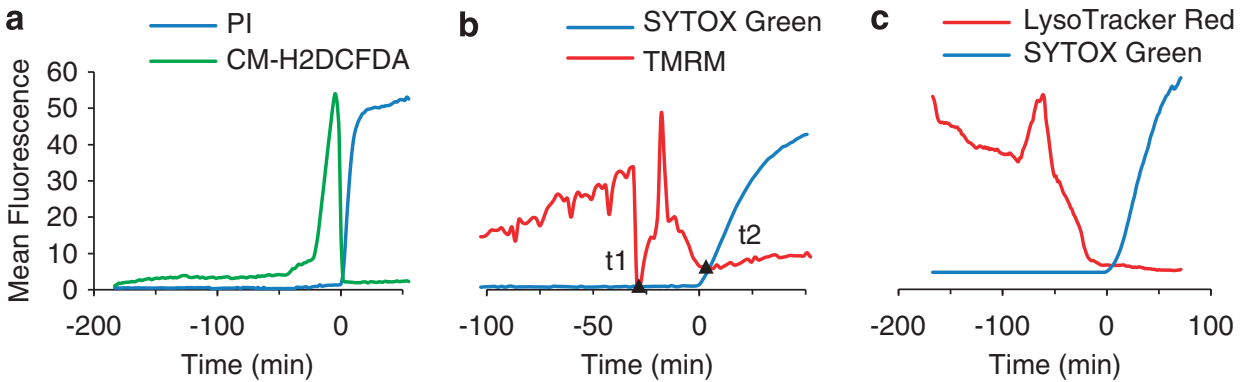

Figure 4 ROS production, mitochondrial hyperpolarization and LMP during secondary necrosis. Graphic representations of the mean fluorescent intensities of (a) CM$\mathrm{H}_{2}$ DCFDA (indicating ROS accumulation), and PI (blue, indicating PMP), (b) of TMRM (directly proportional to MTP), and SYTOX Green (blue, indicating PMP) of a representative single cell. Typical reduction in MTP in apoptosis (t1) is followed by hyperpolarization (t1-t2) and consequent PMP (t2). Graphic representations of the mean intensities of (c) LysoTracker Red DND-99 (inversely proportional to lysosomal leakage) and SYTOX Green (blue). In all conditions apoptosis was induced in L929sAhFas cells by anti-Fas $(500 \mathrm{ng} / \mathrm{ml})$ and images were taken at intervals of $90 \mathrm{~s}$
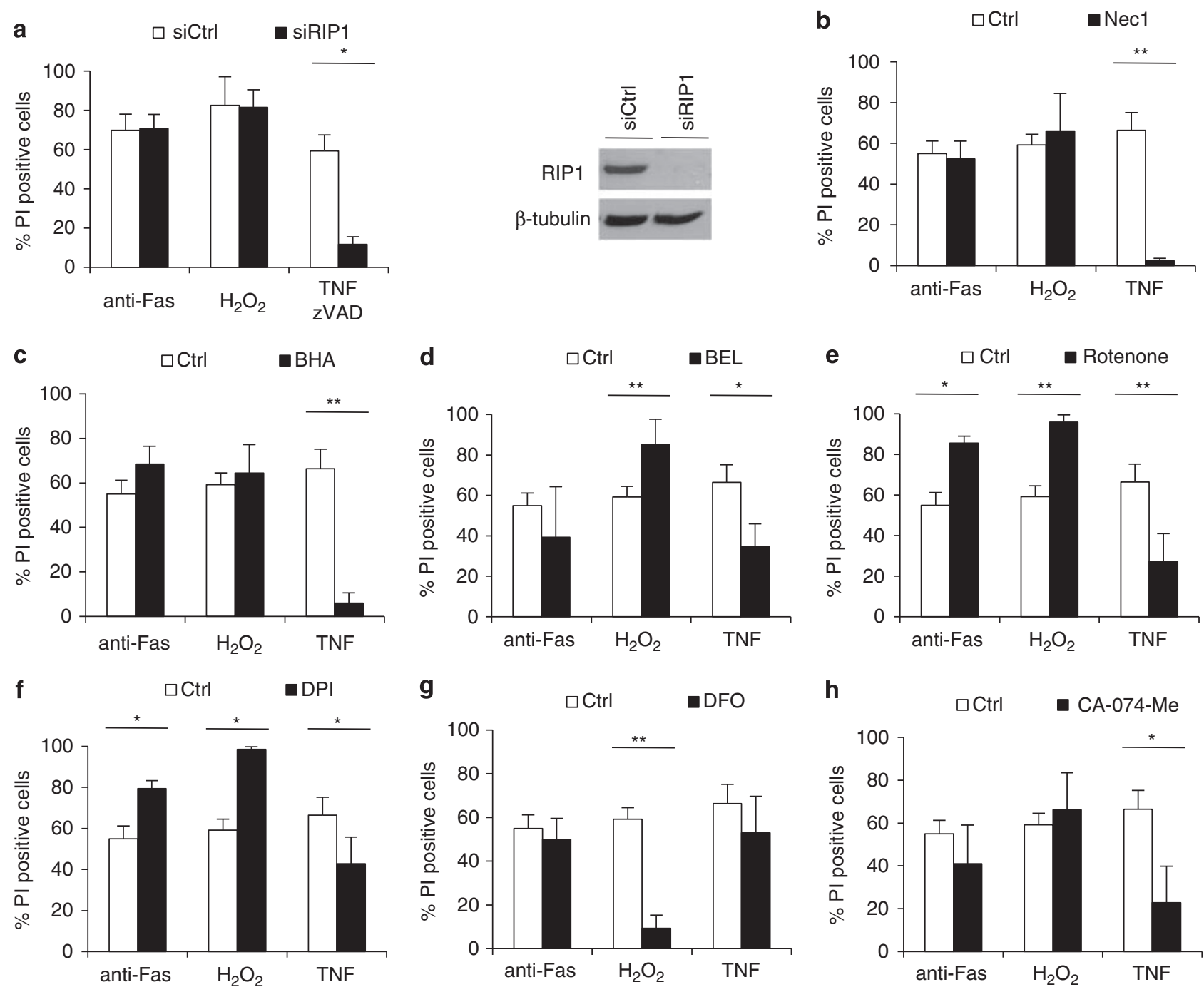

Figure 5 TNF-induced necroptosis depends on RIP1 kinase, mitochondrial complex I and $c P L A_{2}$ activities, whereas $\mathrm{H}_{2} \mathrm{O}_{2}$-induced necrosis requires iron-dependent Fenton reactions. Flow fluorocytometric analysis of the percentage of PI-positive cells on stimulation of L929sAhFas cells with anti-Fas, $\mathrm{H}_{2} \mathrm{O}_{2}$ or TNF after transfection with RIP1 siRNA (a), in the presence or absence of Nec-1 (b, inhibitor of RIP1 kinase), BHA (c, anti-oxidant), BEL (d, inhibitor of $c$ PLA $A_{2}$ ), rotenone (e, inhibitor of mitochondrial complex I), DPI (f, inhibitor of Nox1), DFO ( $\mathbf{g}$, iron chelator) or CA-074-Me ( $\mathbf{h}$, inhibitor upstream of LMP ${ }^{36}$ ). Time points at which about $60 \%$ cell death occurred in the control setup were selected out of at least three independent experiments and compared with the corresponding conditions involving treatment with inhibitor or siRIP1. Mann-Whitney U-test was used to determine statistical significance. Data are expressed as mean \pm S.D. $\left({ }^{\star} P<0.05 ;{ }^{* \star} P<0.01\right)$ 
inhibits RIP1 kinase activity, ${ }^{1,6}$ completely blocked TNFinduced necroptosis in L929sAhFas (Figure 5b and Supplementary Figure 3f) and MEF cells (Supplementary Figure 4a). In contrast, Nec-1 did not affect $\mathrm{H}_{2} \mathrm{O}_{2}$-induced necrosis or anti-Fas-induced secondary necrosis (Figure 5b, Supplementary Figures 3d-e and 4b).

Studies have reported that necrotic killing of L929 cells by TNF involves mitochondrial complex I-mediated ROS production $^{22}$ and $\mathrm{cPLA}_{2}$ activity. ${ }^{23}$ Butylated hydroxyanisole (BHA) efficiently inhibits TNF-induced necrotic cell death but not $\mathrm{H}_{2} \mathrm{O}_{2}$-induced necrosis or anti-Fas-induced secondary necrosis (Figure $5 c$, Supplementary Figure $3 d-f$ ). Inhibiting $\mathrm{cPLA}_{2}$ by bromoenol lactone (BEL) or mitochondrial complex I by rotenone substantially delayed the onset of TNF-induced necroptosis, but did not block $\mathrm{H}_{2} \mathrm{O}_{2}$-induced necrosis and anti-Fas-induced secondary necrosis (Figure $5 \mathrm{~d}-\mathrm{e}$ and Supplementary Figure $3 g-1)$. Instead, cell death was even accelerated when anti-Fas- or $\mathrm{H}_{2} \mathrm{O}_{2}$-stimulated cells were treated with rotenone and when $\mathrm{H}_{2} \mathrm{O}_{2}$-stimulated cells were incubated with BEL. Knockdown of $\mathrm{CPLA}_{2}$ or a chaperone involved in the assembly of mitochondrial complex I, the NADH dehydrogenase (ubiquinone) $1-\alpha$ subcomplex assembly factor 1 (NDUFAF1), resulted in a similar inhibition of TNF-induced necroptosis (Supplementary Figure $5 c$ and d), whereas no inhibition was observed in $\mathrm{H}_{2} \mathrm{O}_{2}$-induced necrosis and anti-Fas-induced secondary necrosis (Supplementary Figure $5 a, b$ and $d$ ). In concordance with the data of Kim et al., ${ }^{24}$ inhibition of Nox 1 by diphenylene iodonium (DPI) also significantly delayed TNF-induced necroptosis, whereas it accelerated $\mathrm{H}_{2} \mathrm{O}_{2}$-induced necrosis and anti-Fas-induced secondary necrosis (Figure $5 f$ and Supplementary Figure 3j-I). Similar results were obtained in TNF-stimulated L929sA cells stably overexpressing CrmA (L929sACrmA), which is a cell death model for sensitized necroptosis (Supplementary Figure $3 \mathrm{~m}) .{ }^{25}$ We conclude that in contrast to TNF, $\mathrm{H}_{2} \mathrm{O}_{2}$ induced necrosis and anti-Fas-induced secondary necrosis in L929sAhFas cells does not rely on RIP1, cPLA $A_{2}$ activity or mitochondrial complex I-dependent ROS production.

Differential role of Fenton-type reactions during different types of necrosis. The previous data clearly show that $\mathrm{H}_{2} \mathrm{O}_{2}$-induced necrosis does not rely on RIP1, mitochondrial complex I-mediated ROS production or $\mathrm{CPLA}_{2}$. However, the live-cell imaging data above suggest that LMP may have an initiating role in $\mathrm{H}_{2} \mathrm{O}_{2}$-induced necrosis. A report by Kurz et al. ${ }^{26}$ demonstrated that an interaction between $\mathrm{H}_{2} \mathrm{O}_{2}$ and redox-active iron ions is required to initiate cellular damage. As intralysosomal iron chelation can protect against $\mathrm{H}_{2} \mathrm{O}_{2}$-induced cell death, ${ }^{27}$ we analyzed the effect of the iron chelator desferrioxamine (DFO) on TNF- and $\mathrm{H}_{2} \mathrm{O}_{2}$-induced necrosis in L929sAhFas cells. DFO effectively blocked $\mathrm{H}_{2} \mathrm{O}_{2}$-induced necrosis, regardless of the concentration of $\mathrm{H}_{2} \mathrm{O}_{2}$ used, but did not affect TNFinduced necroptosis or anti-Fas-induced secondary necrosis (Figure $5 \mathrm{~g}$ and Supplementary Figure $3 \mathrm{a}-\mathrm{c}$ ). Similar results on DFO pretreatment were obtained in MEF cells stimulated with TNF or $\mathrm{H}_{2} \mathrm{O}_{2}$ (Supplementary Figure $4 \mathrm{a}$ and b) or on using the lipophilic iron chelator salicylaldehyde isonicotinoyl hydrazone (SIH) instead of DFO (Supplementary Figure 6). ${ }^{27}$ These observations indicate that Fenton-type reactions and consecutive LMP are crucial in $\mathrm{H}_{2} \mathrm{O}_{2}$-induced necrosis, but not in TNF-induced necroptosis or in anti-Fas-induced secondary necrosis. Indeed, the timing of LMP in TNFinduced necroptosis indicates that it is a late event coinciding with cellular disintegration, as in the case of secondary necrosis (Figures $3 \mathrm{~b}$ and $4 \mathrm{c}$ ). To confirm this differential induction mechanism of LMP in TNF-induced necroptosis and $\mathrm{H}_{2} \mathrm{O}_{2}$-induced necrosis, we analyzed the effect of CA-074-Me, which was shown to block cell death by acting upstream of LMP in a cathepsin B-independent manner. ${ }^{28}$ This inhibitor significantly blocked TNF-induced necroptosis, whereas $\mathrm{H}_{2} \mathrm{O}_{2}$-induced necrosis and anti-Fas-induced secondary necrosis remained unaffected (Figure $5 \mathrm{~h}$ and Supplementary Figure $3 \mathrm{~g}-\mathrm{i})$. In this manner, the differential inhibitory action of both inhibitors, DFO and CA-074-Me, on TNF-induced necroptosis and $\mathrm{H}_{2} \mathrm{O}_{2}$-induced necrosis underscores the different induction mechanisms of LMP.

\section{Discussion}

Recent research has uncovered several forms of cell death that are distinct from classical apoptosis. ${ }^{1,5}$ In this report, we analyzed subcellular events during necroptosis, necrosis and secondary necrosis in the same cellular context by using highresolution time-lapse imaging. TNF induces a regulated form of necrotic cell death, also called necroptosis, ${ }^{6}$ whereas $\mathrm{H}_{2} \mathrm{O}_{2}$ elicits necrosis due to physicochemical insult. Fas-mediated apoptosis consists of a highly regulated signaling phase, which, in the absence of phagocytosis, is followed by a cellular disintegration phase called secondary necrosis. To distinguish the signaling pathways elicited during necroptosis and necrosis, we performed mechanistic studies to resolve the molecular signaling pathways implicated and compared the subcellular events at the level of mitochondria and lysosomes.

Comparative analysis of TNF- and $\mathrm{H}_{2} \mathrm{O}_{2}$-induced cell death by time-lapse imaging confirmed the absence of apoptotic morphological features. Instead, we observed that both cell death stimuli induced typical necrotic morphological features. In some cell types, moderate concentrations of $\mathrm{H}_{2} \mathrm{O}_{2}(<100 \mu \mathrm{M})$ induce apoptosis. ${ }^{10}$ However, we were unable to detect caspase activity or apoptotic morphology at any cytotoxic concentration of $\mathrm{H}_{2} \mathrm{O}_{2}$ (Supplementary Figure $1 \mathrm{i}$ and $\mathrm{j}$, data not shown). It should be noted that zVAD-fmk did not sensitize cells for $\mathrm{H}_{2} \mathrm{O}_{2}$ treatment, in contrast to its effect on TNF-induced necroptosis (Supplementary Figure $1 \mathrm{k}$ and $\mathrm{I}$ ), indicating the implication of distinct necrotic signaling pathways between TNF and $\mathrm{H}_{2} \mathrm{O}_{2}$. This is in contrast to previous studies reporting that in MEF cells both TNF- and $\mathrm{H}_{2} \mathrm{O}_{2}$-induced necrosis rely on RIP1. ${ }^{21}$ However, in our study, RIP1-deficient MEF cells are indeed protected against TNF-induced necroptosis, but do not exhibit altered sensitivity to $\mathrm{H}_{2} \mathrm{O}_{2}$-induced necrosis compared with wild-type MEF cells (Supplementary Figure 7). Moreover, addition of Nec-1, a RIP1 kinase inhibitor, ${ }^{7}$ did not protect primary MEF cells against the cytotoxic activity of $\mathrm{H}_{2} \mathrm{O}_{2}$, but attenuated TNF-induced necroptosis (Supplementary Figure 4). These results demonstrate that in L929sAhFas and MEF cells, $\mathrm{H}_{2} \mathrm{O}_{2}$-induced necrosis, in contrast to TNF-induced necroptosis, is RIP1 independent.

Inhibitors of mitochondrial complex I, cPLA $\mathrm{A}_{2}$ and Nox1, retard TNF-induced necroptosis, pointing to the involvement 
of mitochondrial, membrane and lysosomal subcellular compartments in necrotic cell death. ${ }^{29}$ In this respect, there is extensive documentation that mitochondrial complex Imediated ROS production contributes to necroptosis. ${ }^{22,30,31}$ The multiple effects of $\mathrm{BHA}$ as a mitochondrial complex I inhibitor, oxygen radical scavenger and $\mathrm{CPLA}_{2}$ inhibitor explain its strong antinecrotic effects on TNF-induced necroptosis. ${ }^{30} \mathrm{BHA}$ also completely abrogated zVAD-fmkmediated sensitization of mice to TNF lethality. ${ }^{32}$ In contrast, $\mathrm{H}_{2} \mathrm{O}_{2}$-induced necrosis occurs independently of the abovementioned signaling pathways. Our time-lapse imaging data demonstrate that lysosomes rapidly start leaking on addition of $\mathrm{H}_{2} \mathrm{O}_{2}$. Preincubation with the iron chelator, DFO, which accumulates in lysosomes after endocytic uptake, ${ }^{27}$ completely blocked $\mathrm{H}_{2} \mathrm{O}_{2}$-induced necrosis. In contrast, the same treatment hardly affects TNF-induced necroptosis in L929sAhFas and MEF cells, suggesting differential involvement of Fenton-type reactions. An attempt to link the described molecular signaling events to individual subcellular biochemical events, that is, LMP, oxidative burst and mitochondrial hyperpolarization, failed because of phototoxicity. A combination of inhibitor, probes and repetitive light exposure was toxic without the addition of the cell death stimulus, TNF or $\mathrm{H}_{2} \mathrm{O}_{2}$. Therefore, we were unable to address this question.

Time-lapse imaging data demonstrate that TNF-induced necroptotic cell death consists of a signaling phase and a cellular disintegration phase. In contrast, $\mathrm{H}_{2} \mathrm{O}_{2}$-induced necrosis starts immediately with the cellular disintegration phase. During the signaling phase of TNF-induced necrosis, the gradual increase in ROS formation is most likely dependent on mitochondrial complex I and/or Nox1, because inhibitors of either enzyme significantly retard TNF-induced ROS production and necroptosis. ${ }^{22,24,31}$ The steady increase in ROS generation in TNF-induced necroptosis is followed by mitochondrial hyperpolarization at the end of the signaling phase, and consequent rounding of cells, LMP and oxidative burst. Mitochondrial hyperpolarization has been attributed to increased oxygen consumption and increased electron flow. ${ }^{17}$ However, it is also conceivable that RIP1-mediated inhibition of the adenine nucleotide transporter ${ }^{33}$ results in a reduction in the mitochondrial matrix levels of ADP, leading to a decrease in ATP synthase activity or to its reverse activity. The latter mechanism instead hydrolyzes ATP and pumps protons against the electrochemical gradient to the mitochondrial inner membrane space, ${ }^{34}$ resulting in increased MTP. Apparently, this MTP increase occurs with a biphasic pattern, but the reason for this remains unclear. Generally, the fluorescence of probes that monitor MTP is quenched when accumulating in mitochondria. ${ }^{35}$ TMRM has been reported to induce intramitochondrial self-quenching at the concentration applied in this study $(200 \mathrm{nM}){ }^{36}$ Typically, on mitochondrial uncoupling, a transient increase in TMRM fluorescence partially reflects decreased intramitochondrial self-quenching. To exclude the possibility that the monitored increase in MTP is not indicative of an actual decrease, we performed an additional control experiment by treating TMRM-loaded cells with a mitochondrial uncoupler, carbonyl cyanide m-chlorophenyl hydrazone (CCCP). Using $200 \mathrm{nM}$ of TMRM, a small transient increase of $10 \%$ is observed before the final reduction in the presence of CCCP (Supplementary Figure 8a). This initial increase is not observed using $30 \mathrm{nM}$ TMRM (Supplementary Figure 8b), confirming the data of Ward et al. ${ }^{36}$ However, we would like to emphasize that the increase in mean fluorescence observed during necrotic cell death is 10 -fold higher than in the case of CCCP. Therefore, we conclude that the observed mitochondrial hyperpolarization is not because of intramitochondrial self-quenching.

Schematic representations illustrate the timing of subcellular events in TNF- and $\mathrm{H}_{2} \mathrm{O}_{2}$-induced necrosis and in Fas-mediated secondary necrosis (Figure 6a-c), using PMP as a reference point. In all three types of necrotic cell death, the cellular disintegration phase is characterized by a continuous decrease in LMP until the eventual loss of PMP.

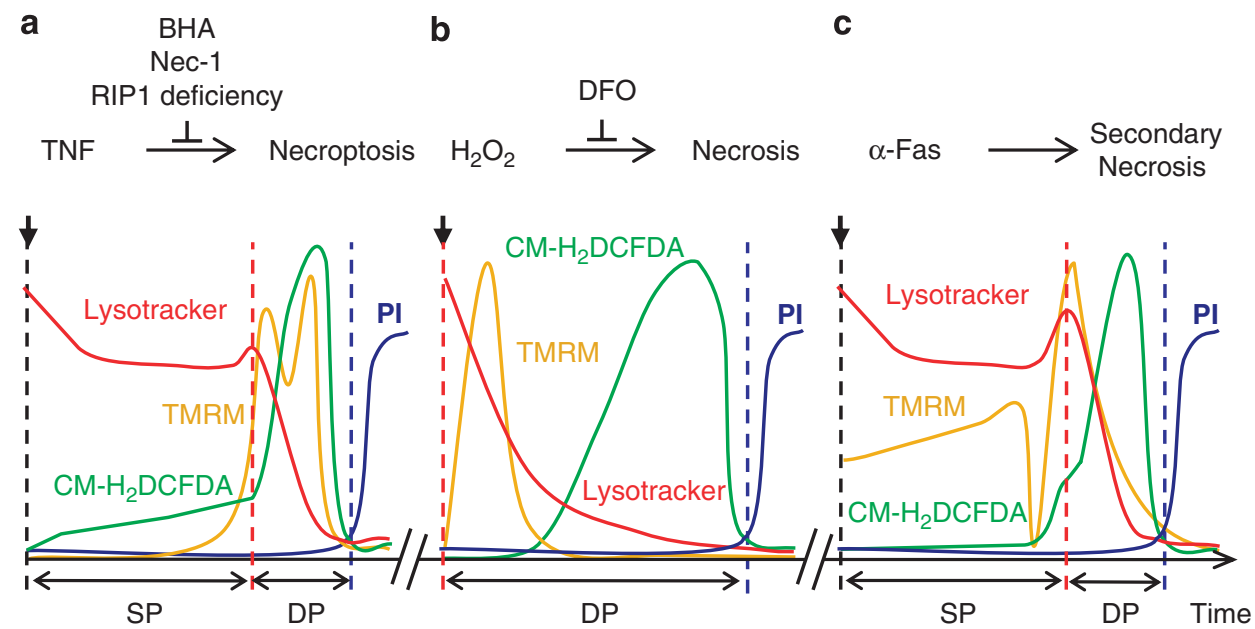

Figure 6 Schematic comparison of several subcellular events in TNF- and $\mathrm{H}_{2} \mathrm{O}_{2}$-induced necrosis, and of anti-Fas induced apoptosis in function of time. Simplified diagrammatic representation of ROS formation (green), MTP (orange), LMP (red) and PMP (blue) over time. Necrosis induced by (a) TNF and (b) $\mathrm{H}_{2} \mathrm{O}_{2}$, and secondary necrosis induced by (c) anti-Fas. TNF is blocked by BHA, Nec-1 or RIP1 deficiency, but $\mathrm{H}_{2} \mathrm{O}_{2}$-induced necrosis is not. On the other hand, $\mathrm{H}_{2} \mathrm{O}_{2}$, but not TNF-induced necroptosis, is blocked by DFO. SP, signaling phase; DP, disintegration phase 
This gradual LMP coincides with mitochondrial hyperpolarization and a burst of ROS production. The occurrence of secondary necrosis is often regarded as an in vitro artifact because of the absence of phagocytic capacity. However, in extreme cases of extensive apoptosis and insufficient phagocytic capacity in vivo, it may have a (patho)physiological role. Lysosomal disintegration leading to the release of cathepsins, and oxidative burst may participate in the generation of modified damage-associated molecular patterns (DAMPs) through proteolysis ${ }^{37}$ and generation of oxidized products. ${ }^{38}$ In that respect, the cellular disintegration phase serves as a last life-buoy to attract immune competent cells and to initiate regeneration processes.

In conclusion, the cellular disintegration phase of the three types of necrosis (necroptosis, necrosis and secondary necrosis) is characterized by the same sequence of subcellular events, such as LMP, mitochondrial hyperpolarization, oxidative burst and eventually PMP. Moreover, the finding that LMP in apoptosis only occurs during the secondary necrosis phase may clarify the debate on the role and timing of LMP in apoptosis. Our time-lapse imaging results indicate that LMP in necroptosis and secondary necrosis is a late process coinciding with the cellular disintegration phase. Therefore, it is unlikely that LMP has an important signaling function during apoptosis itself, but it may contribute to the generation of DAMP molecules. A better understanding of the impact of necrotic signaling pathways and cellular disintegration process in homeostasis and pathophysiology could lead to therapeutic opportunities in immunotherapy and regenerative medicine. The importance of chemical-induced necrosis by oxidative stress is further underscored by the potential use of metal-protein-attenuating compounds in the treatment of patients with chronic anemia or neurodegenerative diseases. ${ }^{15}$

\section{Materials and Methods}

Cells. L929sAhFas and L929sACrmA cells were generated by expressing human Fas gene or a viral serpin-like caspase inhibitor, CrmA, in the L929sA cells, a TNF-sensitive derivative of the murine fibrosarcoma cell line L929. ${ }^{39}$ These cells and MEF were cultured in Dulbecco's modified Eagle's medium, supplemented with $10 \%$ fetal calf serum, penicillin $(100 \mathrm{U} / \mathrm{ml})$, streptomycin $(0.1 \mathrm{mg} / \mathrm{ml})$ and L-glutamine $(0.03 \%)$. MEF cells were grown in low oxygen conditions $\left(3 \% \mathrm{O}_{2}\right) .{ }^{40}$

Antibodies, cytokines and reagents. Recombinant human and mouse TNF were produced to at least $99 \%$ homogeneity in our laboratory and have a specific biological activity of $6.8 \times 10^{7}$ and $3.3 \times 10^{8} \mathrm{IU} / \mathrm{mg}$, respectively. Antihuman Fas antibodies (clone 2R2) were purchased from Cell Diagnostica (Munster, Germany). Propidium iodide (Becton Dickinson, Franklin Lakes, NJ, USA) was used at $3 \mu \mathrm{M}$ for live-cell imaging and at $30 \mu \mathrm{M}$ for flow fluorocytometric analysis. SYTOX Green, LysoTracker Red, 5-(and-6)-chloromethyl-2' ${ }^{\prime} 7^{\prime}$-dichlorodihydrofluorescein diacetate acetyl ester (CM- $\left.\mathrm{H}_{2} \mathrm{DCFDA}\right)$ and tetramethyl rhodamine methyl ester (TMRM) (Molecular Probes - Invitrogen, Carlsbad, CA, USA) were used at $10,50 \mathrm{nM}, 1 \mu \mathrm{M}$ and $200 \mathrm{nM}$, respectively. The caspase peptide inhibitor, benzyloxycarbonyl-Val-Ala-Asp(Ome)-fluoromethylketone (zVAD-fmk) (Bachem, Bubendorf, Switzerland), was used at $10 \mu \mathrm{M}$. DFO, BEL, BHA, DPI chloride, CCCP, 3-(4,5-dimethylthiazol-2-yl)-2,5-diphenyltetrazolium bromide (MTT) and cycloheximide (Sigma Aldrich, St. Louis, MO, USA) were used at $1 \mathrm{mM}, 30,100$, $15,50 \mu \mathrm{M}, 500 \mu \mathrm{g} / \mathrm{ml}$ and $10 \mu \mathrm{g} / \mathrm{ml}$, respectively. 5-(Indol-3-ylmethyl)-(2-thio-3methyl)hydantoin (Nec-1, Calbiochem, San Diego, CA, USA), cathepsin inhibitor IV (CA-074-Me, Calbiochem) and rotenone (MP Biomedicals Europe N.V., Illkirch, France) were used at 10,50 and $25 \mu \mathrm{M}$, respectively. The cell permeable iron chelator, SIH (a kind gift from Prof. Dr. U Brunk), was used at $10 \mu \mathrm{M}$. The murine RIP1 antibody was purchased from Becton Dickinson, and the antibodies for detecting actin and $\beta$-tubulin as loading controls were from MP Biomedicals and Abcam (Cambridge, UK), respectively. CPLA $A_{2}$ and NDUFAF1 antibodies were obtained from Cell Signaling Technology (Danvers, MA, USA) and Bio-Connect B.V. (Te Huissen, The Netherlands), respectively.

Analysis of cell death and cell survival parameters. For flow fluorocytometric analysis, cells were kept in suspension plates before analysis (Sarstedt, Newton, NC, USA). For MTT colorimetric analysis, L929sAhFas and MEF cells were seeded in 96-well plates. After preincubating cells with the mentioned inhibitors for $1 \mathrm{~h}$ (except for DFO, which needs $3 \mathrm{~h}$ preincubation), hTNF (10 000 IU/ $\mathrm{ml}), \mathrm{H}_{2} \mathrm{O}_{2}(2 \mathrm{mM})$ or anti-Fas $(500 \mathrm{ng} / \mathrm{ml})$ was added for different durations for flow fluorocytometric analysis. For MTT analysis, serial dilutions of $h T N F, \mathrm{H}_{2} \mathrm{O}_{2}$ or antiFas were used. Caspase activity was analyzed by a fluorogenic substrate assay. ${ }^{39}$ Cell death was analyzed for loss of membrane integrity by measuring PI uptake (flow fluorocytometric analysis). Cell survival was analyzed by measuring succinate dehydrogenase (complex II) activity (MTT assay).

RNAi-mediated knockdown of RIP1. L929sAhFas cells were transfected according to the manufacturer's protocol in six-well plates with $10 \mathrm{nM}$ RIP1 siRNA, $\mathrm{CPLA}_{2}$ siRNA, NDUFAF1 siRNA or Non-Targeting siRNA (ON-TARGETplus SMART pool siRNA, Dharmacon, Thermo Fisher Scientific, Waltham, MA, USA) using INTERFERin (Polyplus-transfection SA, Illkirch, France) as a transfection reagent. After $72 \mathrm{~h}$, cells were trypsinized, counted and placed in suspension plates for FACS analysis. At $96 \mathrm{~h}$ after transfection, L929sAhFas cells were stimulated with the mentioned trigger and lysates were obtained. Efficiency of knockdown was analyzed by western blot, as previously described. ${ }^{39}$

Imaging setup. L929sAhFas cells were seeded in cover glass-based eight-well chamber slides (Lab-Tek, Nunc, VWR International, Leuven, Belgium) or in one-well glass bottom dishes (Willco Wells B.V., Amsterdam, The Netherlands). Cells were loaded with fluorescent probes for 15-30 min before treatment with TNF ( $10000 \mathrm{IU} /$ $\mathrm{ml})$ in the presence of $\mathrm{ZVAD}$-fmk $(10 \mu \mathrm{M}), \mathrm{H}_{2} \mathrm{O}_{2}(500 \mu \mathrm{M})$ or anti-Fas $(250 \mathrm{ng} / \mathrm{ml})$, depending on the probes. Cells were imaged using the Application Solution MultiDimensional Workstation (AS MDW) (Leica Microsystems, Mannheim, Germany).

The AS MDW includes a DM IRE2 microscope equipped with an HCX PL APO $63 \times / 1.3$ glycerin-corrected $37^{\circ} \mathrm{C}$ objective and a 12-bit Coolsnap HQ Camera (Roper Scientific GmbH, Ottobrunn, Germany). The objective is equipped with a PIFOC P-Piezo element that allows images to be taken in the $z$-direction in a precise and reproducible manner. Three-dimensional live-cell imaging ( $x, y, z, t$ and $\lambda$ ) was performed in differential interference contrast and multiple fluorescence modes. The fluorescent probes were excited with a xenon burner $(45 \mathrm{~W})$ in front of a monochromator. Excitation/emission was set depending on the fluorescent probes: $\mathrm{PI}$, excitation at $541 \mathrm{~nm}$, cube BP515-560/FT580/LP590; SYTOX Green, excitation at $490 \mathrm{~nm}$, cube BP470/40/FT500/BP525/50; CM-CH $\mathrm{CHCFDA}_{2}$ excitation at $488 \mathrm{~nm}$, cube BP470/40/FT500/BP525/50; TMRM, excitation at $540 \mathrm{~nm}$, cube BP515-560/FT580/LP590; LysoTracker Red DND-99, excitation at $535 \mathrm{~nm}$, cube BP515-560/FT580/LP590.

Image acquisition. For analysis of fluorescent signals, cells were monitored at three or four positions $(x, y)$ in each condition for 4 or $6 \mathrm{~h}$. For each condition, at least two independent experiments were run and analyzed. During each imaging event, $z$-sections were made in differential interference contrast and epifluorescence modes with a step size of $1 \mu \mathrm{m}$ over a total depth of $11 \mu \mathrm{m}$. To minimize phototoxicity and photobleaching, the camera was used in binning mode 2, the power of the xenon burner was attenuated with a neutral density filter and exposure time was kept to a minimum. To control for effects due to phototoxicity, untreated cells were imaged for at least $4 \mathrm{~h}$ using the same fluorochromes and time intervals; no major changes in fluorescence and morphology were observed (Supplementary Figure 2).

After acquisition. The 16-bit 3D-image sequence was opened in ImageJ using a custom macro. The best focus was selected and a maximum intensity projection was made at each time point and saved as a timestack multitiff. Using a second macro, graphs of mean fluorescence intensity integrated over the entire cell area over time were calculated and presented as graphs, images and movies. In addition, graphic data for the different fluorophores were automatically exported to a spreadsheet file. We analyzed the indicated number of cells. Synchronous cellular behavior was observed of multiple cells within the field of focus and was 
representative of all monitored positions (data not shown). A description of the contents of the supplementary videos is provided in Supplementary Table 2.

\section{Conflict of interest}

The authors declare no conflict of interest.

Acknowledgements. We thank Dr. Boris Chernyak, Dr. Pierre Golstein and Dr. Saskia Lippens for critical feedback and discussions, Isabel Vanoverberghe for lab assistance, and Dr. A Bredan for editing. We are grateful to Prof. Dr. M Kelliher for sending us the RIP1K-deficient MEF cells. Dr. TVB and Dr NF are paid by a postdoctoral fellowship from FWO (Fonds Wetenschappelijk Onderzoek Vlaanderen), NV obtained a predoctoral fellowship from the BOF, Ghent University. PV is holder of a Methusalem grant from the Flemish Government. This work has been supported by Flanders Institute for Biotechnology (VIB) and several Grants from the European Union (EC Marie Curie Training and Mobility Program, FP6, ApopTrain, MRTN-CT-035624; EC RTD Integrated Project, FP6, Epistem, LSHB-CT-2005-019067, APO-SYS, FP7, HEALTH-F4-2007-200767), the Interuniversity Poles of Attraction-Belgian Science Policy (IAP6/18), the Fonds voor Wetenschappelijk Onderzoek - Vlaanderen (G.0133.05 and 3G.0218.06), and the Special Research Fund of Ghent University (Geconcerteerde Onderzoekstacties 12.0505.02).

1. Degterev A, Yuan J. Expansion and evolution of cell death programmes. Nat Rev 2008; 9 : 378-390.

2. Vanlangenakker $N$, Vanden Berghe $T$, Krysko DV, Festjens N, Vandenabeele P. Molecular mechanisms and pathophysiology of necrotic cell death. Cur Mol Med 2008; 8: 207-220.

3. Hitomi J, Christofferson DE, Ng A, Yao J, Degterev A, Xavier RJ et al. Identification of a molecular signaling network that regulates a cellular necrotic cell death pathway. Cell 2008; 135: $1311-1323$

4. Festjens N, Vanden Berghe T, Vandenabeele P. Necrosis, a well-orchestrated form of cell demise: signalling cascades, important mediators and concomitant immune response. Biochim Biophys Acta 2006; 1757: 1371-1387.

5. Kroemer G, Galluzzi L, Vandenabeele P, Abrams J, Alnemri ES, Baehrecke EH et al. Classification of cell death: recommendations of the Nomenclature Committee on Cell Death 2009. Cell Death Differ 2009; 16: 3-11.

6. Degterev A, Huang Z, Boyce M, Li Y, Jagtap P, Mizushima N et al. Chemical inhibitor of nonapoptotic cell death with therapeutic potential for ischemic brain injury. Nat Chem Biol 2005; 1: 112-119.

7. Degterev A, Hitomi J, Germscheid M, Ch'en IL, Korkina O, Teng X et al. Identification of RIP1 kinase as a specific cellular target of necrostatins. Nat Chem Biol 2008; 4: 313-321.

8. Vandenabeele P, Declercq W, Vanden Berghe T. Necrotic cell death and 'necrostatins': now we can control cellular explosion. TIBS 2008; 33: 352-355.

9. Declercq W, Vanden Berghe T, Vandenabeele P. RIP kinases at the crossroads of cell death and survival. Cell 2009; 138: 229-232.

10. Li W, Yuan X, Nordgren G, Dalen H, Dubowchik GM, Firestone RA et al. Induction of cell death by the lysosomotropic detergent MSDH. FEBS Lett 2000; 470: 35-39.

11. Schroder $E$, Eaton $P$. Hydrogen peroxide as an endogenous mediator and exogenous tool in cardiovascular research: issues and considerations. Curr Opin Pharmacol 2008; 8: 153-159.

12. Babior BM. NADPH oxidase: an update. Blood 1999; 93: 1464-1476.

13. Yu Z, Persson HL, Eaton JW, Brunk UT. Intralysosomal iron: a major determinant of oxidant-induced cell death. Free Radic Biol Med 2003; 34: 1243-1252.

14. Terman A, Gustafsson B, Brunk UT. Autophagy, organelles and ageing. J Pathol 2007; 211: 134-143.

15. Doraiswamy PM, Finefrock AE. Metals in our minds: therapeutic implications for neurodegenerative disorders. Lancet Neurol 2004; 3: 431-434.

16. Goldstein JC, Waterhouse NJ, Juin P, Evan GI, Green DR. The coordinate release of cytochrome $\mathrm{c}$ during apoptosis is rapid, complete and kinetically invariant. Nat Cell Biol 2000; 2: 156-162.

17. Goossens V, De Vos K, Vercammen D, Steemans M, Vancompernolle K, Fiers W et al. Redox regulation of TNF signaling. Biofactors 1999; 10: 145-156.
18. Krysko DV, D'Herde K, Vandenabeele P. Clearance of apoptotic and necrotic cells and its immunological consequences. Apoptosis 2006; 11: 1709-1726.

19. Holler N, Zaru R, Micheau O, Thome M, Attinger A, Valitutti S et al. Fas triggers an alternative, caspase-8-independent cell death pathway using the kinase RIP as effecto molecule. Nat Immun 2000; 1: 489-495.

20. Lin Y, Choksi S, Shen HM, Yang QF, Hur GM, Kim YS et al. Tumor necrosis factor-induced nonapoptotic cell death requires receptor-interacting protein-mediated cellular reactive oxygen species accumulation. J Biol Chem 2004; 279: 10822-10828.

21. Shen HM, Lin Y, Choksi S, Tran J, Jin T, Chang $L$ et al. Essential roles of receptorinteracting protein and TRAF2 in oxidative stress-induced cell death. Mol Cell Biol 2004; 24: 5914-5922.

22. Goossens V, Stange G, Moens K, Pipeleers D, Grooten J. Regulation of tumor necrosis factor-induced, mitochondria- and reactive oxygen species-dependent cell death by the electron flux through the electron transport chain complex I. Antioxid Redox Signal 1999; 1: 285-295.

23. Hayakawa M, Ishida N, Takeuchi K, Shibamoto S, Hori T, Oku N et al. Arachidonic acidselective cytosolic phospholipase A2 is crucial in the cytotoxic action of tumor necrosis factor. J Biol Chem 1993; 268: 11290-11295.

24. Kim YS, Morgan MJ, Choksi S, Liu ZG. TNF-induced activation of the Nox1 NADPH oxidase and its role in the induction of necrotic cell death. Mol Cell 2007; 26: $675-687$.

25. Vercammen D, Beyaert R, Denecker G, Goossens V, Van Loo G, Declercq W et al. Inhibition of caspases increases the sensitivity of L929 cells to necrosis mediated by tumor necrosis factor. J Exp Med 1998; 187: 1477-1485.

26. Kurz T, Leake A, Von Zglinicki T, Brunk UT. Relocalized redox-active lysosomal iron is an important mediator of oxidative-stress-induced DNA damage. Biochem J 2004; 378 (Part 3): 1039-1045

27. Kurz T, Gustafsson B, Brunk UT. Intralysosomal iron chelation protects against oxidative stress-induced cellular damage. FEBS J 2006; 273: 3106-3117.

28. Mihalik R, Imre G, Petak I, Szende B, Kopper L. Cathepsin B-independent abrogation of cell death by CA-074-OMe upstream of lysosomal breakdown. Cell Death Differ 2004; 11 : 1357-1360.

29. Hentze H, Lin XY, Choi MS, Porter AG. Critical role for cathepsin B in mediating caspase-1dependent interleukin-18 maturation and caspase-1-independent necrosis triggered by the microbial toxin nigericin. Cell Death Differ 2003; 10: 956-968.

30. Festjens N, Kalai M, Smet J, Meeus A, Van Coster R, Saelens X et al. Butylated hydroxyanisole is more than a reactive oxygen species scavenger. Cell Death Differ 2006; 13: $166-169$

31. Schulze-Osthoff K, Bakker AC, Vanhaesebroeck B, Beyaert R, Jacob WA, Fiers W. Cytotoxic activity of tumor necrosis factor is mediated by early damage of mitochondrial functions. Evidence for the involvement of mitochondrial radical generation. $\mathrm{J}$ Biol Chem 1992; 267: 5317-5323.

32. Cauwels A, Janssen B, Waeytens A, Cuvelier C, Brouckaert P. Caspase inhibition causes hyperacute tumor necrosis factor-induced shock via oxidative stress and phospholipase A2. Nat Immun 2003; 4: 387-393.

33. Temkin V, Huang $Q$, Liu H, Osada H, Pope RM. Inhibition of ADP/ATP exchange in receptor-interacting protein-mediated necrosis. Mol Cell Biol 2006; 26: 2215-2225.

34. Grover GJ, Marone PA, Koetzner L, Seto-Young D. Energetic signalling in the control of mitochondrial F1F0 ATP synthase activity in health and disease. Int J Biochem Cell Biol 2008; 40: 2698-2701.

35. Scaduto Jr RC, Grotyohann LW. Measurement of mitochondrial membrane potential using fluorescent rhodamine derivatives. Biophys J 1999; 76 (1 Part 1): 469-477.

36. Ward MW, Huber HJ, Weisova P, Dussmann H, Nicholls DG, Prehn JH. Mitochondrial and plasma membrane potential of cultured cerebellar neurons during glutamate-induced necrosis, apoptosis, and tolerance. J Neurosci 2007; 27: 8238-8249.

37. Pacheco FJ, Servin J, Dang D, Kim J, Molinaro C, Daniels T et al. Involvement of lysosomal cathepsins in the cleavage of DNA topoisomerase I during necrotic cell death. Arthritis Rheum 2005; 52: 2133-2145.

38. Kazama H, Ricci JE, Herndon JM, Hoppe G, Green DR, Ferguson TA. Induction of immunological tolerance by apoptotic cells requires caspase-dependent oxidation of high-mobility group box-1 protein. Immunity 2008; 29: 21-32.

39. Vanden Berghe T, Kalai M, van Loo G, Declercq W, Vandenabeele P. Disruption of HSP90 function reverts tumor necrosis factor-induced necrosis to apoptosis. J Biol Chem 2003; 278: 5622-5629.

40. Parrinello S, Samper E, Krtolica A, Goldstein J, Melov S, Campisi J. Oxygen sensitivity severely limits the replicative lifespan of murine fibroblasts. Nat Cell Biol 2003; 5: $741-747$. 